\title{
An Audit of Admissions to Intensive Care Unit at Kamuzu Central Hospital in Malawi
}

\author{
Rodwell Gundo ${ }^{1}$, Edoly Shirley Lengu ${ }^{1}$, Alfred Maluwa ${ }^{2}$, Onias Mtalimanja ${ }^{3}$, \\ Deliwe Chipeta $^{3}$, Clement Kadyaudzu ${ }^{3}$ \\ ${ }^{1}$ Medical-Surgical Nursing Department, Kamuzu College of Nursing, University of Malawi, Lilongwe, Malawi \\ ${ }^{2}$ Research Directorate, Kamuzu College of Nursing, University of Malawi, Lilongwe, Malawi \\ ${ }^{3}$ Intensive Care Unit, Kamuzu Central Hospital, Lilongwe, Malawi \\ Email: aomaluwa@kcn.unima.mw
}

Received 19 April 2014; revised 31 May 2014; accepted 30 June 2014

Copyright (C) 2014 by authors and Scientific Research Publishing Inc.

This work is licensed under the Creative Commons Attribution International License (CC BY).

http://creativecommons.org/licenses/by/4.0/

(c) (i) Open Access

\begin{abstract}
Results are presented of a retrospective audit of admissions to the Intensive Care Unit (ICU) of Kamuzu Central Hospital in Lilongwe, Malawi, which is a tertiary referral facility. The audit was conducted for a period of one year spanning from January to December, 2012. The objectives of the audit were to: describe the profile of admissions and treatment outcomes of the admissions and identify main causes of mortality in ICU of the facility. The admission book and patients' records were reviewed retrospectively guided by a data extraction form which was specifically designed for this study. The extracted data included age, sex, referring unit, diagnosis, treatment outcome and length of stay. The data were analyzed using STATA version 10.0. A total of 253 patients were admitted to the ICU over the one year period of study. About a third of the patients $(33.6 \% \mathrm{n}=85)$ were admitted due to postoperative surgery. There were 154 deaths representing an overall mortality of $60.9 \%$. Sepsis was the commonest cause of death and accounted for $39.6 \%$, $\mathrm{n}=\mathbf{6 1}$ of the deaths. Younger age of less than 40 years and increased patients' length of stay in the unit were significantly and positively associated with mortality $(P<0.05)$. The high mortality rates among patients admitted to ICU reflects numerous challenges at various levels of critical care service delivery in the country. There is therefore a need to strengthen critical care services to improve treatment outcomes for patients admitted to ICU of the facility.
\end{abstract}

\section{Keywords}

ICU Admission, Head Injuries, Retrospective ICU Audit, Sepsis, Length of ICU Stay

\section{Introduction}

An intensive care unit (ICU) is a designated unit within a hospital which is specially staffed and equipped to

How to cite this paper: Gundo, R., Lengu, E.S., Maluwa, A., Mtalimanja, O., Chipeta, D. and Kadyaudzu, C. (2014) An Audit of Admissions to Intensive Care Unit at Kamuzu Central Hospital in Malawi. Open Journal of Nursing, 4, 583-589.

http://dx.doi.org/10.4236/ojn.2014.48061 
provide observation, care and treatment of patients with actual or potential life threatening illness or injury, from which recovery is possible [1]. Compared to developed countries where intensive care services are well established, intensive care practice in developing countries is still at an early stage of development despite the high burden of critical illnesses.

Malawi has 4 Central hospitals, two of which (Queen Elizabeth Central Hospital in Blantyre and Zomba Central Hospital in Zomba) are in the south. Kamuzu Central Hospital is located in Lilongwe, the central region of the country and Mzuzu Central Hospital in the north. These Central hospitals are tertiary referral facilities for the lower level facilities such as the district hospitals, health centres and other private hospitals in the respective districts within each region.

The Central region, which is the catchment area for Kamuzu Central hospital is one of the densely populated regions of Malawi, with a total population of 5,510,195 people [2]. The facility offers specialised care to patients referred from 9 district hospitals and other private health facilities within the region. The facility also serves as a teaching hospital for various cadres such as medical doctors, nurses, clinical officers and anaesthetic clinical officers.

The ICU at Kamuzu Central hospital admits both adults and children and has 5 beds representing $0.5 \%$ of the total number of beds at the facility. At the time of this study, there were three ventilators, five cardiac monitors with some non-functional parameters, pulse oximetry, capnometer, oxygen concentrator and cylinders at the Kamuzu Central hospital's ICU. There were no services for arterial blood gas analysis. Laboratory investigations which include full blood count, blood chemistry, grouping and cross matching were done at the hospital's laboratory which served the whole hospital. A laboratory for University of North Carolina (UNC) project, located at the hospital, assisted with full blood count and blood chemistry when the hospital's laboratory was unable to conduct these investigations.

The ICU was attached to the hospital's Main Operating Theatre and was run by anaesthesia department. There was a resident clinical officer in the unit and was supported by anaesthetic clinical officers who were not physician graduates but just specially trained nurses and medical assistants. There were nine nurses; none of them had undergone specialised training in intensive care nursing. Admission of patients to the unit was at the discretion of the resident clinician and anaesthetic clinical officers who were consulted by medical doctors and surgeons from different departments. Majority of the patients admitted to the unit were those that required mechanical ventilation.

In addition to the ICU which was the setting for this study, the hospital had a four bedded gynaecological/obstetric high dependency unit, five bedded surgical high dependency unit, six bedded paediatric high dependency unit and a four-bedded medical high dependency unit. None of these units ventilated patients. Although challenges to critical care practice in developing countries have been highlighted [3], there is limited information on ICU admissions and their outcomes in these countries. The objectives of this audit were therefore to; describe the profile of admissions, treatment outcomes and identify main causes of mortality in the intensive care unit at Kamuzu Central Hospital in Malawi.

\section{Methodology}

\subsection{Design and Sampling}

This was a retrospective audit of admissions to the Intensive Care Unit for a period of one year spanning from January to December, 2012. The records of all patients that were admitted within the study period were included in the audit. Records from other units and departments of the facility other than those from the ICU were excluded from the study.

\subsection{Data Collection}

The study used routine Health Management Information System (HMIS) data. In particular, the admission book in the unit and patients' records were retrospectively reviewed. Tracing of the patients' records was done with assistance of a clerk who was handling the records in the unit. Data collection was done by two nurses who worked in the unit. A data collection guide was developed and used to extract the following data; age, sex, referring unit, diagnosis, treatment outcome and length of stay. The primary diagnosis was subdivided into head injury, medical condition, polytrauma, gynaecological/obstetric condition, postoperative surgical condition and other surgical conditions. 


\subsection{Data Analysis}

Data were analyzed using STATA version 10.0. Descriptive statistics were computed for the variables (age, sex, referring unit, diagnosis, treatment outcome and length of stay). The results are presented as frequencies and percentages in tables and graphs. Chi-square test was used to determine association between the explanatory variables (diagnosis and length of stay) and the response variable (treatment outcome). The test level of significance was $5 \%$.

\subsection{Ethical Consideration}

The study was exempted from review by National Health Sciences Research Committee (NHSRC) on the basis that audits were not required to undergo ethical review. However, permission to publish the audit findings is required and was sought from the NHSRC. Institutional clearance was granted by the management of Kamuzu Central Hospital for the audit to be conducted at the facility.

\section{Results}

\section{Profile of Admissions}

Records of 253 patients that were admitted to the ICU over the study period were reviewed. The mean \pm 1 Standard Error (SE) age for the patients was $29 \pm 1.06$ years. A summary of the profile of the admissions is provided in Table 1.

\section{Treatment Outcome}

The treatment outcome of eight patients (3.2\%) was not recorded, 154 patients (60.9\%) died, 1 patient (0.4\%) was referred to another facility and 90 patients (35.6\%) were discharged from the ICU to step down units (either high dependency unit or general ward). The common cause of death was sepsis which accounted for $39.6 \%, \mathrm{n}=$ 61 , followed by head injury $(16.2 \%, \mathrm{n}=25)$, malaria/meningitis $(7.1 \%, \mathrm{n}=11)$, anaemia/haemorrhage $(5.2 \%, \mathrm{n}$ $=8)$, polytrauma $(5.2 \%, n=8)$, eclampsia $(5.2 \%, n=8)$, pneumonia $(4.5 \%, n=7)$. Shortage of blood for transfusion was the cause of death for 3 patients (1.9\%) and the other causes of death accounted for $13.2 \%(n=20)$. There were 4 patients (2.6\%) that died but the causes of their death were not recorded.

Most of the patients that died were those aged between 21 and 30 years (Figure 1). The age group below 40 years accounted for $76.5 \%(n=118)$ of the deaths. Young age (less than 40 years) was significantly and positively associated with high mortality $(\mathrm{P}<0.05)$.

The number of deaths showed a declining trend within 12 hours of stay in the ICU and also after 6 days of stay in the ICU (Figure 2). Most of the deaths $(61.6 \%, \mathrm{n}=93)$ occurred between 12 hours and 6 days of stay in the ICU (Figure 2). These results are due to the fact that most of the deaths were caused by sepsis. In addition, there was a significant positive association between length of hospital stay and mortality $(\mathrm{P}<0.05)$.

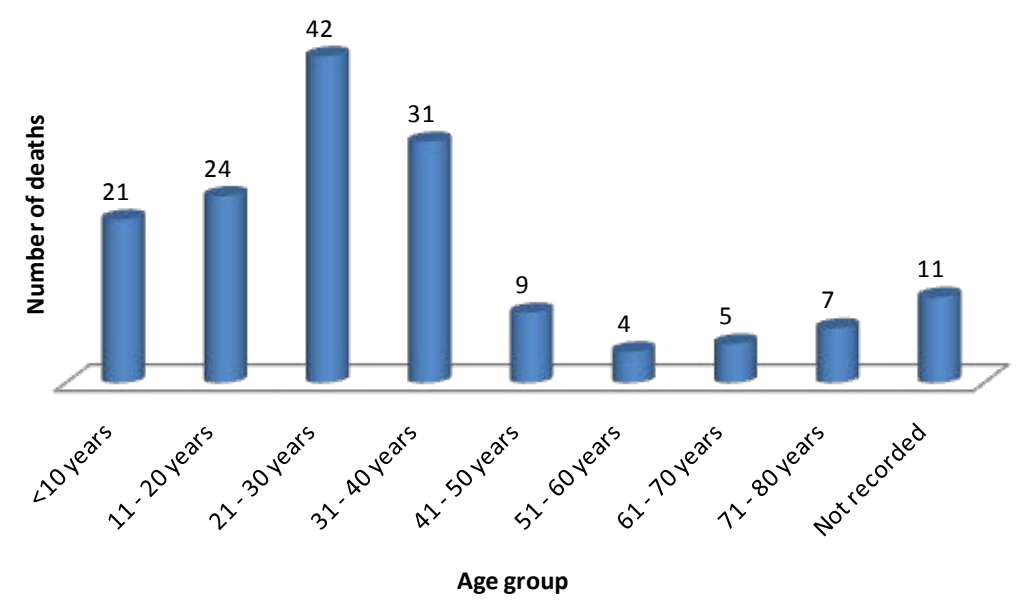

Figure 1. Mortality in relation to patients' age $(P=0.003, n=154)$ 
Table 1. Profile of patients that were admitted at the Kamuzu Central Hospital ICU from January to December, 2012.

\begin{tabular}{|c|c|}
\hline Variable & N (\%) \\
\hline \multicolumn{2}{|l|}{ Sex } \\
\hline Female & $114(45.1 \%)$ \\
\hline Male & 135 (53.4\%) \\
\hline Not recorded & $4(1.6 \%)$ \\
\hline \multicolumn{2}{|l|}{ Age distribution } \\
\hline$<10$ years & $33(13 \%)$ \\
\hline $11-20$ years & $36(14.2 \%)$ \\
\hline $21-30$ years & $57(22.5 \%)$ \\
\hline 31 - 40 years & $54(21.3 \%)$ \\
\hline $41-50$ years & $18(7.1 \%)$ \\
\hline $51-60$ years & $8(3.2 \%)$ \\
\hline $61-70$ years & $6(2.4 \%)$ \\
\hline$>70$ years & $8(3.2 \%)$ \\
\hline Not recorded & $33(13 \%)$ \\
\hline \multicolumn{2}{|l|}{ Source of admission } \\
\hline Casualty Department & $27(10.7 \%)$ \\
\hline Children Ward & $21(8.3 \%)$ \\
\hline Maternity ward & $43(17 \%)$ \\
\hline Medical Ward & $8(3.2 \%)$ \\
\hline Private/CHAM Hospitals & $3(1.2 \%)$ \\
\hline Main Operating Theatre & $28(11 \%)$ \\
\hline Short Stay Department & $8(3.2 \%)$ \\
\hline Surgical High Dependency Unit & $8(3.2 \%)$ \\
\hline Surgical Ward (1A) & $6(2.4 \%)$ \\
\hline District Hospitals & $2(0.8 \%)$ \\
\hline Not recorded & $100(39.5 \%)$ \\
\hline \multicolumn{2}{|l|}{ Diagnosis } \\
\hline Head Injury & $44(17.4 \%)$ \\
\hline Medical condition & $48(19 \%)$ \\
\hline Obstetric/Gynaecological condition & $59(23.3 \%)$ \\
\hline Polytrauma & $14(5.5 \%)$ \\
\hline Post operative surgical conditions & $85(33.6 \%$ \\
\hline Other surgical conditions & $3(1.2 \%)$ \\
\hline
\end{tabular}

\section{Discussion}

This study has described the profile of admissions and their treatment outcome in intensive care unit over a period of one year. Surgical conditions constituted majority of admissions. These results are supported by results of previous studies which also reported that most of the patients admitted to ICU in the developing world were surgical cases [4] [5]. In light of this growing evidence, there is need for strengthening surgical care in these 


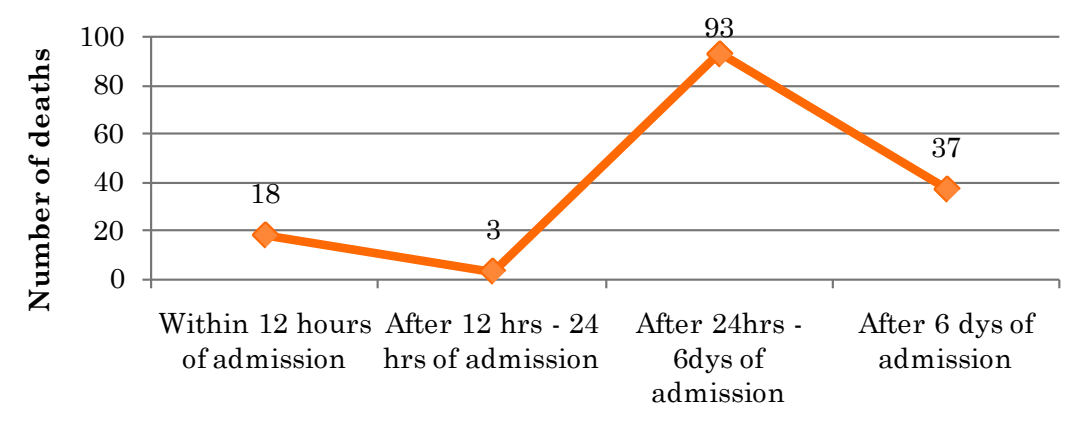

Patients' length of stay in ICU

Figure 2. Patient mortality in relation to the length of stay in the ICU $(P=0.042, n$ =151).

countries to reduce the burden of surgical diseases on critical care services.

Head injury and polytrauma also contributed significant number of admissions. Although the cause of these injuries was not included in the extracted data, it was observed that most of the injuries were a result of road traffic accidents. The World Health Organization Global Status on road safety [6] reported that 1.3 million people die every year in road traffic accidents globally, of which 90\% occur in developing countries which ironically possess $48 \%$ of the world's registered vehicles [6]. Most of the accidents are a result of careless driving and use of road unworthy vehicles. Results show that there is a need for serious interventions in the prevention of road accidents in the developing countries including Malawi.

Mortality was noted to be higher than that reported in a previous audit of admissions in 2010 in the same ICU [7]. This may be attributed to general increase the number of admissions at the facility [2]. Contrary to what was reported in a previous audit in 2010, [7] the results show that patients that were below the age of 40 were associated with high mortalities. In addition, increased patients' length of stay in ICU was also associated with high mortality. The results are due to the fact that in this study most patients were admitted with critical conditions which could not be reversed. As also reported in previous studies [7] high mortalities are a result of weaknesses in scoring of severity of illness in resource-limited countries in the absence appropriate laboratory services which constitute parameters of the scoring systems [8], [9]. Results therefore show that there is a need for a limited resource setting disease severity scoring systems at the facility.

Although the extracted data did not include employment status of the patients but the 2010 Malawi Demographic and Health Survey [2] reported that $56 \%$ and $82 \%$ of females and males respectively within the age group of 15 - 49 years in Malawi were employed. The loss of citizens within this age group is therefore an issue of serious concern to the economy of the country as the most productive people are dying early.

Sepsis was the common cause of death. This could be attributed to insufficient early sepsis care and lack of resources in managing patients with sepsis. For instance, blood culture and sensitivity was rarely done at the facility. As observed by Baelani et al., [10] most African countries particularly in sub-Saharan Africa are not able to implement the Surviving Sepsis Campaign guidelines due to lack of resources. Therefore there is a need for the country to increase financial resource allocation to the facility so that surviving sepsis campaign guidelines can be implemented in full at the facility, thus improving patient outcomes as the major cause of mortality will have been eliminated.

The study results show that some patients in the ICU, died due to preventable causes of death. For example, the deaths of the 3 patients that died due to shortage of blood at the blood bank for transfusion. These deaths could be prevented if blood was readily available in the blood bank. There is therefore a need to intensify campaigns for blood donation to help patients in dire need of blood during emergencies. In addition the death of a patient with sepsis who died as a result of electricity black out while on a ventilator could also have been prevented. Therefore, ventilators with back-up batteries or standby generators should be installed in the ICU to protect the lives of patients undergoing mechanical ventilation in case of electricity blackouts.

Results show that some of the records of patients who died could not be traced in the facility's records. In addition, the tracing of records for patients that were discharged from the unit was also difficult. Lengu et al., [11] also reported that documentation at the same facility including the other tertiary facilities in Malawi was poor. The results also agree those that were reported by Rodden and Bell [12] in their study in the United Kingdom in 
which documentation was described as a forgotten skill by healthcare workers. These results are reported despite the fact that documentation is a legal requirement [13] and allows hospital staff to share information about patients. Therefore, it is recommended that the facility authorities should strengthen record keeping and also consider electronic recording and storage of patients' data.

\section{Limitations of the Study}

Some of the required data about the patients could not be found in the admission book which is provided by the Health Management Information System (HIMS) department.

\section{Conclusion}

Intensive care practice is still undeveloped in developing countries despite the increased burden of illnesses requiring this type of care. Most of the patients were admitted at the ICU of Kamuzu Central Hospital due to surgical conditions, with head injuries and polytrauma being the most common causes of the admissions. Results show that over $50 \%$ of the patients in this study died. The high mortalities are a result of weakness in scoring severity of illness which is common in resource constrained countries due to the absence of appropriate laboratory services. There is therefore a need to strengthen the ICU so that it is able to score severity of illness among the admitted patients. Mortality was high in patients below the age of 40 , which is also the most productive age of the population, probably due to increased road accidents among this age group. Sepsis was the major cause of death among the patients due to lack of resources to manage the patients and most of the patients died between 12 hours and 6 days after being admitted in the ICU. There is therefore a need to strengthen the ICU with equipment and supplies for the management of sepsis. Other areas that need strengthening include ensuring constant availability of blood for transfusion and installation of standby generators to supplement the mains for the operation of ICU equipment during blackouts caused by power failure. Results calls for the strengthening of ICU in order to optimize positive patient outcomes.

\section{References}

[1] Dunser, M.W., Baelani, I. and Ganbold, L. (2006) A Review and Analysis of Intensive Care Medicine in the Least Developed Countries. Critical Care Medicine, 34, 1234-1242.

http://dx.doi.org/10.1097/01.CCM.0000208360.70835.87

[2] NSO (2011) National Statistical Office and ICF Macro. Malawi Demographic and Health Survey 2010. Zomba, and Calverton: NSO and ICF Macro.

[3] Fowler, A.R., Adhikari, N.K.J. and Bhagwanjee, S. (2008) Clinical Review: Critical Care in the Global ContextDisparities in Burden of Illness, Access and Economics. Critical Care, 12. http://dx.doi.org/10.1186/cc6984

[4] Towey, R.M. and Ojara, S. (2007) Intensive Care in Developing World. Anaesthesia, 62, 32-37. http://dx.doi.org/10.1111/j.1365-2044.2007.05295.x

[5] Bickler, S.W. and Spiegel, D. (2010) Improving Surgical Care in Low-and Middle-Income Countries: A Pivotal Role for the World Health Organization. World Journal of Surgery, 34, 386-390.

http://dx.doi.org/10.1007/s00268-009-0273-2

[6] World Health Organization (2009) Global Status Report on Road Safety. http://www.who.int/violence_injury_prevention/road_safety_status/2009/en/

[7] Tomlison, J., Kadyaudzu, C., Samuel, C., Campbell, L.P. and Charles, A.G. (2013) The Burden of Surgical Disease on Critical Care Services at a Tertiary Hospital in Sub-Saharan Africa. Tropical Doctor, 43, 27-29. http://dx.doi.org/10.1177/0049475513480773

[8] Size, M., Borgstein, E.S. and Haisma, H.J. (2005) One-Year Audit of Admissions to the Intensive Care Unit of the Queen Elizabeth Central Hospital, Blantyre. Malawi Medical Journal, 17, 12-14. http://dx.doi.org/10.4314/mmj.v17i1.10863

[9] Ilori, I.U. and Kalu, Q.N. (2012) Intensive Care Admissions and Outcome at the University of Calabar Teaching Hospital, Nigeria. Journal of Critical Care, 27, 105.e1-105.e4.

[10] Baelani, I., Jochbeger, S., Laimer, T., Otieno, D., Kabutu, J., Wilson, I., Baker, T. and Dunser, M.W. (2011) Availability of Critical Care Resources to Treat Patients with Severe Sepsis or Septic Shock in Africa: A Self-Reported, Continent-Wide Survey of Anaesthesia Providers. Critical Care, 15, R10. http://dx.doi.org/10.4314/mmj.v17i1.10863

[11] Lengu, E.S., Gundo, R., Maluwa, A. and Mbirimtengerenji, N. (2013) Compliance of State Registered Nurses to Nurs- 
ing Standards during Practice in Tertiary Facilities in Malawi. Open Journal of Nursing, 3, 395-399. http://dx.doi.org/10.4236/ojn.2013.35053 (http://www.scirp.org/journal/ojn/)

[12] Rodden, C. and Bell, M. (2002) Record Keeping: Developing Good Practice. Nursing Standard, 17, 40-42. www.ncbi.nlm.nih.gov/pubmed/12360739. http://dx.doi.org/10.7748/ns2002.09.17.1.40.c3268

[13] Trenoweth, M.C. (2007) Succeeding in Nursing and Midwifery Education. John Wiley \& Sons, West Sussex. 
Scientific Research Publishing (SCIRP) is one of the largest Open Access journal publishers. It is currently publishing more than 200 open access, online, peer-reviewed journals covering a wide range of academic disciplines. SCIRP serves the worldwide academic communities and contributes to the progress and application of science with its publication.

Other selected journals from SCIRP are listed as below. Submit your manuscript to us via either submit@scirp.org or Online Submission Portal.
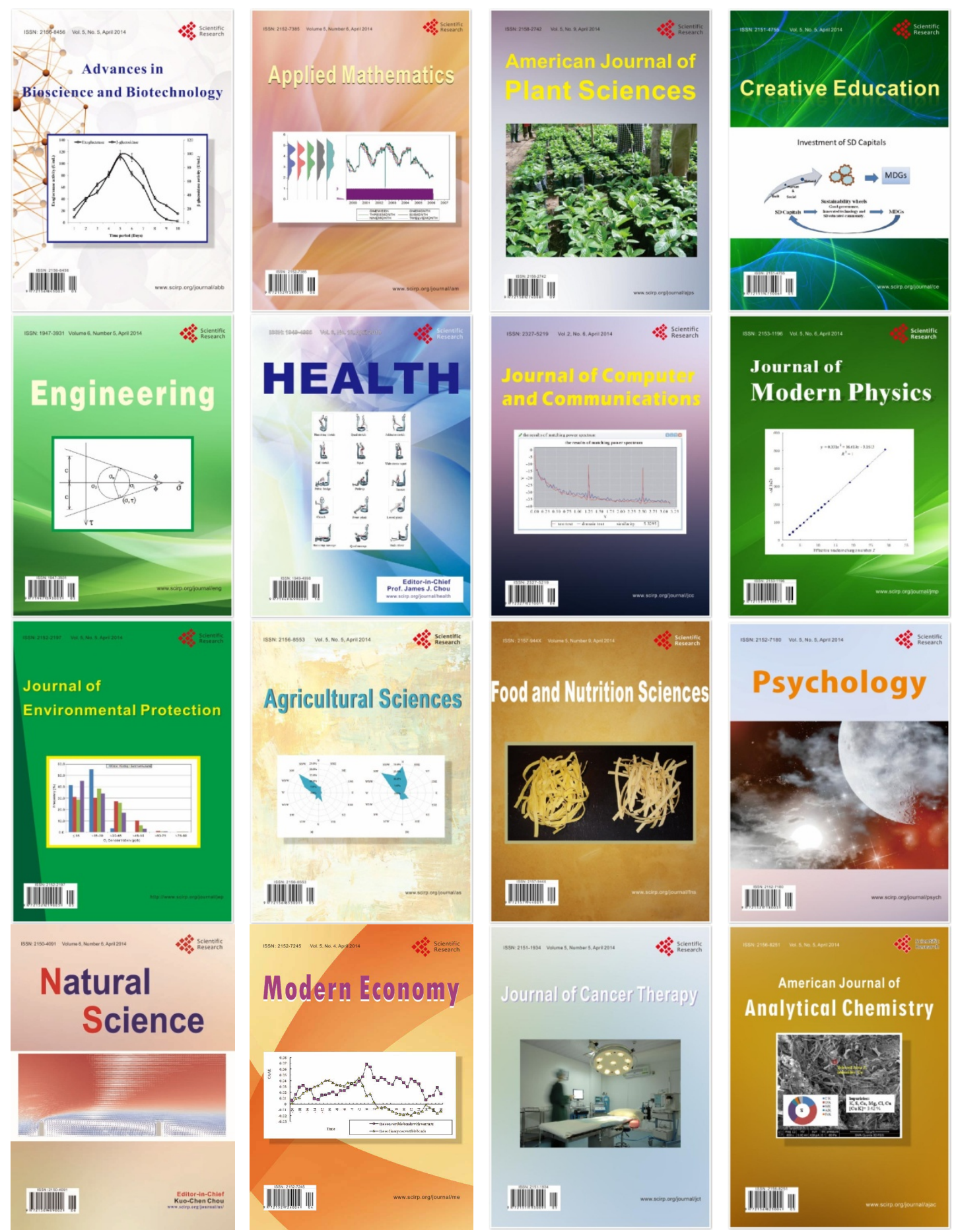